Discussion Paper No. 06-088

\title{
Distributional Effects of the High School Degree in Germany
}

Johannes Gernandt, Michael Maier, Friedhelm Pfeiffer, and Julie Rat-Wirtzler

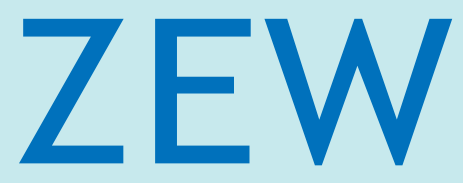

Zentrum für Europäische Wirtschaftsforschung $\mathrm{GmbH}$

Centre for European

Economic Research 
Discussion Paper No. 06-088

\title{
Distributional Effects of the High School Degree in Germany
}

\author{
Johannes Gernandt, Michael Maier,
} Friedhelm Pfeiffer, and Julie Rat-Wirtzler

Download this ZEW Discussion Paper from our ftp server:

ftp://ftp.zew.de/pub/zew-docs/dp/dp06088.pdf

Die Discussion Papers dienen einer möglichst schnellen Verbreitung von neueren Forschungsarbeiten des ZEW. Die Beiträge liegen in alleiniger Verantwortung der Autoren und stellen nicht notwendigerweise die Meinung des ZEW dar.

Discussion Papers are intended to make results of ZEW research promptly available to other economists in order to encourage discussion and suggestions for revisions. The authors are solely responsible for the contents which do not necessarily represent the opinion of the ZEW. 


\section{Non technical summary}

The high school degree is the most important general educational qualification in Germany. Since 1960 the number of grammar schools which lead to this degree as well as the number and share of successful graduates in a cohort distinctly increased. Even though the influence of schooling on various labour market outcomes is a central topic of the economics of education, empirical knowledge on long run impacts of the rising share of workers with a high school degree in Germany is still rare. Given the debate on the possibly negative effect of the German educational system of early tracking on equality of educational opportunities, this is surprising. For educational policy reasons, empirical knowledge on long run impacts of the educational expansion on socio-economic outcomes such as employment or wages seems to be essential.

This paper is concerned with the impact of a high school degree on the wage distribution in the period from 1984 to 2004, which has not been investigated so far. In this period, the share of male workers with such a degree increased from 16 to 25 percent (in our GSOEP samples). Empirical knowledge of the impact of the high school degree on the whole wage distribution might be valuable for several reasons. General competencies learned at grammar school may yield higher returns in complex tasks and high wage jobs. In particular, grammar schools might be also helpful for individuals with low productivity. If labour market returns with a high school degree were higher for students with low productivity (and low wages), grammar schools could possibly provide a valuable tool for improving individual education and the productivity of the workforce.

The empirical findings result from comparisons of quantiles of the estimated wage distributions of individuals with and without the degree. We distinguish the overall quantile treatment effects (OQTE) from the quantile treatment effects on the treated (QTET). The latter effect (QTET) assesses the impact of grammar school for those workers who studied there while the former (OQTE) assesses the impact for the whole population of workers. The samples consist of twenty-one cross-sections of German male workers from the GSOEP 1984 to 2004. Our findings suggest that the OQTEs are positive and significant, while the QTETs are statistically not different from zero. This suggests that the selection of students into grammer schools might have been too restrictive. For more workers higher education would have raised their productivity and wages. Furthermore, there seems to be some evidence that the impact of the high school degree on the upper part of the wage distribution has declined slightly. In our application, social status of the family is the driving force of grammar school attendance, confirming earlier findings from the literature. Children of better educated parents seem to be endowed with attitudes and skills, which are valuable for educational and labour market success. Future research to investigate skill formation in families seems to be fruitful for educational policy reason. 


\title{
Distributional Effects of the High School Degree in Germany
}

\author{
Johannes Gernandt*, Michael Maier*, \\ Friedhelm Pfeiffer** and Julie Rat-Wirtzler* \\ *ZEW Mannheim \\ ** ZEW Mannheim, University of Mannheim
}

\begin{abstract}
:
This paper investigates the impact of a high school degree on the wage distribution in the period from 1984 to 2004 in Germany. In that period the share of male workers with a high school degree increased from 16 to 25 percent. An econometric evaluation estimator is used to analyze quantile treatment effects for the whole population of male workers and for the subpopulation of workers with a high school degree. It turns out that the impact of a high school degree on the wage distribution for all workers is positive, whereas its impact on the wage distribution of the workers with a high school degree does statistically not differ from zero. This suggests that the selection of students into grammer schools might have been too restrictive. For more workers higher education would have raised their productivity and wages.
\end{abstract}

\section{Keywords:}

Economic returns to secondary education, econometric evaluation, quantile treatment effects, educational expansion.

JEL-classification: C14, C21, J31

\section{Acknowledgements:}

Friedhelm Pfeiffer acknowledges financial support form the German Science Foundation under grants PF 331/2 ("Microeconometric Methods to Assess Heterogeneous Returns to Education") and PF 331/3 ("Wages, Rent-Sharing and Collective Wage Bargaining"). Our special thanks go to Andreas Ammermüller, Gunhild Berg, Bernd Fitzenberger and Anton Flossmann for helpful comments. All remaining errors are ours.

\section{Corresponding author:}

Friedhelm Pfeiffer, Centre for European Economic Research, P.O. Box 103443, D-68034

Mannheim. Tel.: +49-621-1235-150, E-mail: pfeiffer@zew.de 


\section{Introduction}

The high school degree ("Abitur") is the highest general educational qualification in Germany. Since 1960 the number of grammar schools ("Gymnasium"), where successful students receive a high school degree, increased as well as the number of graduates and the share of students who succeeded in completing their education in these schools. In principle, the German educational system offers various pathways to a high school degree, but grammar schools represent an important and traditional way to receive such a degree (see www.bildungsserver.de). In 2003 there were 3,139 grammar schools in Germany. In West Germany their number increased from 1,823 in 1960 to 2,311 in 1970 (and to 2,446 in 1991, Statistisches Bundesamt, 2005a). So the bulk of the expansion already occurred in the 1960s. While in $19605 \%$ of the overall population in West Germany held a high school degree (Müller, 1998), in the school year 2003/04, $41.5 \%$ of all school leavers finished grammar school (Statistisches Bundesamt, 2005b).

One important aim of the educational expansion was to enhance participation in higher education and to induce more equality of educational opportunities (Bildungsbericht, 2003). Economists are interested in the influence of schooling on various labour market outcomes such as individual human capital or the wage distribution. Despite of an impressive amount of empirical research on returns to education (see section 2 below) the impact of the German high school degree on the wage distribution, which is the focus of this paper, has not been studied so far. This is somewhat surprising given the intensive discussion on the negative impact of early tracking in the German educational system on the distribution of educational outcomes. Schuetz et al. (2005) provide the reader with an introduction to this issue and an empirical analysis of the role of the tracking system based on international student achievement scores; for further evidence see also Dustmann (2004) or Lauer (2005).

The contribution of this paper to the literature on education and its impact on wages is twofold. First of all, the paper investigates the impact of successfully completing grammar school and receiving the corresponding degree on the whole wage distribution. The high school degree is considered as the treatment variable and the paper thus assesses its impact on the wage distribution taking into account the endogeneity of the educational choice. Entering a grammar school in Germany depends among others on ability, social background, time preferences, wage rates and credit constraints. At different quantiles of the wage distribution the impact of the degree is compared to its counterfactual values, i.e. the wage distributions which would result with and without the degree. The estimation of the counterfactual wage distribution is based on the conditional independence assumption, which imposes weaker assumptions on the selection process and individual behaviour than ordinary quantile regressions. 
The analysis of the impact of the high school degree on the wage distribution might be valuable for several reasons. From an economic point of view, general competencies acquired at grammar school may on the one hand lead to higher returns in complex tasks and high wage jobs. This might in turn have an influence on the decision whether to enter grammar school or not. On the other hand, grammar schools could be especially helpful for enhancing general competencies for otherwise low wage workers. For educational policy reasons as well as from a welfare point of view, distributional effects are highly relevant. Since grammar schools are publicly financed, empirical knowledge of their impacts on the wage distribution is a crucial brick to assess their efficiency. Furthermore, if labour market returns for a high school degree were higher for workers with low ability, grammar schools could possibly provide a valuable tool for improving the productivity of the workforce.

Second, the impact on the wage distribution is investigated over the previous two decades. In the period from 1984 to 2004, those graduates who profited from the educational expansion of the sixties entered the labour market and raised the qualification structure of the workforce. In our sample of male workers in WestGermany, extracted from the German Socio-Economic Panel (GSOEP), the share of workers with a high school degree increased from 16 to 25 percent. The question is whether the massive inflow of students with a high school degree had an impact on the wage distribution and if so, how much. It is well known that on the one hand the computer revolution and educational upgrading changed the organisation of labour away from routine manual tasks to non-routine analytical and creative tasks (Autor et al., 2006, Spitz-Oener, 2006). In this process, skill obsolescence was rising for vocational competencies, but not for general ones (Ludwig and Pfeiffer, 2006). On the other hand, due to high unemployment rates wage growth was lower for entrants to the labour market than for incumbent wage workers. Incumbent workers seem to have enjoyed at least some protection against wage competition which might be one reason for the recent rise in wage inequality in Germany (Gernandt and Pfeiffer, 2006, Kohn, 2006, among others).

The impact of the educational expansion and the high school degree on the wage distribution, which has not been investigated so far in this literature, is thus the topic of this paper. Figure 1 starts with an illustration. The wage distribution for the GSOEP samples of workers with and without a high school degree is shown for three out of the 21 available cross-sections (1984, 1994 and 2004). Obviously, workers with a degree receive on average higher wages. Furthermore, in all years the wage distributions for workers with a high school degree show significantly less compression compared to those for workers without such a degree. However, the log wage differences declined nearly at all quantiles over the period of investigation (see Table A1 of the appendix). Furthermore, the decline was stronger in the upper part 
of the distribution. From a descriptive point of view, these findings seem to hint at some changes in the wage distribution over time, especially in its upper part.

Figure 1: Kernel density estimates of the wage distribution for 1984, 1994 and 2004
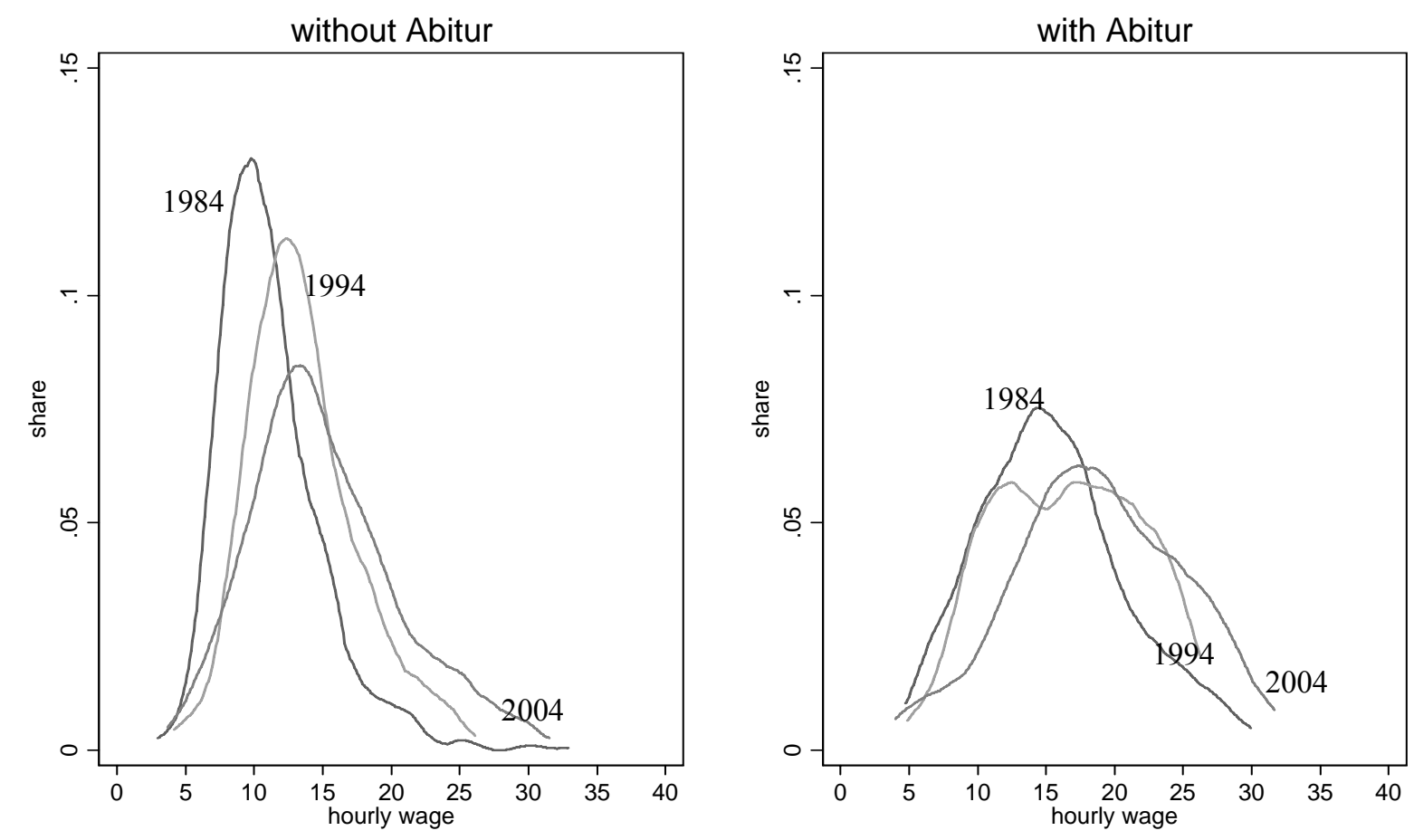

Source: GSOEP 1984-2004, sample of West German male workers aged 16 to 65; own calculations, real wages (basis 2000), see text.

In the econometric part, the differences of counterfactual distributions of wages are studied for the groups of workers with and without a high school degree. Particularly, two effects are examined: the treatment effect on the treated (persons with a high school degree) and the treatment effect for the population of all West German male workers (independent of a high school degree). The latter effect will be called the overall treatment effect of a high school degree.

According to our empirical results, the overall treatment effects are positive and significant, while the treatment effects on the treated are statistically not different from zero. The overall treatment effect differs between quantiles and over time. In the upper part of the wage distribution, the effects are declining over time for all quantiles. However, these differences are not always statistically significant. For the lower part of the wage distribution, the overall treatment effect does not exhibit any clear trend over time. Compared to these results, ordinary quantile regressions yield generally higher effects, which is presumably a consequence of ability bias.

Our findings that the treatment effects on the treated do not statistically differ from zero implies that the counterfactual wage distribution for workers with a high school 
degree does not differ from that which would have emerged if those workers had not obtained a high school degree. From the viewpoint of human capital theory this result is surprising. However it seems to be in line with the literature that points to the selectivity effects of the German system of early ability tracking. As grammar schools select students with high productivity, these students might presumably have also been in the upper part of the wage distribution if they had not obtained a high school degree. This seems to be in line with international findings. In the United States roughly 80 percent of the expected lifetime variation of returns to schooling seems to be independent of the decision to graduate at age 17, Cunha and Heckman (2006).

The paper is organized as follows. Section 2 describes the econometric method applied, while section 3 focuses on the sample and some further descriptive evidence. Section 4 discusses the econometric results and section 5 concludes.

\section{Quantile Treatment Effects}

The aim of the paper is to assess the impact of a high school degree ("Abitur") on the whole wage distribution in Germany by taking into account the endogeneity of educational choices and by evaluating the effect for various quantiles of the wage distribution. In what follows, the overall quantile treatment effect is defined as $\Delta^{\mathrm{OQTE}}$ $=\mathrm{q}_{1 \tau}-\mathrm{q}_{0 \tau}$ which is the difference between the $\tau$-quantiles of the distributions of the latent (or counterfactual) outcomes $Y_{1}$ and $Y_{0}$. $Y_{1}$ hereby represents the wage an individual with a high school degree would receive and $Y_{0}$ the one without such a degree, respectively. Furthermore, the treatment effect for the subpopulation of graduates will be examined and denoted as the Quantile Treatment Effect on the Treated, $\Delta^{\text {QTET }}$. This approach will only identify a causal effect of the high school degree on the wage distribution under the restrictive assumption that the rank of an individual is the same for both of the latent wage distributions (see Chernozhukov and Hansen, 2005 or Firpo, forthcoming).

In the case of selection based on heterogeneous individual impacts of a high school degree, conventional quantile regression methods may lead to biased estimates; for general methodological reviews see for example Imbens (2004) and Angrist (2004). For assessing the causal returns to schooling see also Blundell et al. (2005), Card (2001), Heckman et al. (2006) or Oreopoulos (2006) with numerous applications for returns to schooling in the United Kingdom and the United States. Estimates for homogenous or constant returns to education for Germany reveal values between 5 and 10 percent, depending on the instruments used, whereas the average treatment effect of schooling has been estimated to be of 8.9 percent for West German males, see Flossmann and Pohlmeier (2006).

In order to identify the impact of a high school degree on different wage quantiles, the conditional independence assumption is used. For this assumption to hold, the 
latent outcomes $Y_{1}$ and $Y_{0}$ have to be independent of the binary treatment variable $D$ (equal to one if the individual has successfully completed high school) given a vector of covariates $X$. The choice of $X$ and the plausibility of the conditional independence assumption will be discussed in the next section.

One possibility of using the conditional independence assumption for an assessment of mean treatment effects is the reweighing estimator of Hirano et al. (2003). This approach reweighs the observed outcomes $Y$ (which are equal to $D Y_{1}+(1-D) Y_{0}$ ) by some function of the propensity score (that is, the conditional expectation $\mathrm{E}[D \mid X]$ of the treatment variable) in order to estimate the average treatment effect $\mathrm{E}\left[Y_{1}-Y_{0}\right]$ and the average treatment effect on the treated, $\mathrm{E}\left[Y_{1}-Y_{0} \mid D=1\right]$. The reweighing procedure is a method of expressing expectations of latent outcomes (i.e., $Y_{1}$ and $Y_{0}$ ) by means of expectations of observable (realized) variables $(Y, D$, and $X)$. This follows by conditioning arguments and several applications of the law of iterated expectation; the derivation is carried out in the proof of Lemma 1 of Firpo (forthcoming).

To estimate $\Delta^{\mathrm{OQTE}}$ and $\Delta^{\mathrm{QTET}}$, we employ the approach of Firpo (forthcoming), which is based on the mentioned reweighing method of Hirano et al. (2003). The $\tau-$ quantiles of the latent outcomes $Y_{j}($ for $j=0,1)$ are estimated as

$$
\hat{\mathrm{q}}_{\mathrm{j}, \tau}=\arg \min _{\mathrm{q}} \sum_{\mathrm{i}=1}^{\mathrm{N}} \hat{\omega}_{\mathrm{j}, \mathrm{i}} \rho_{\tau}\left(\mathrm{Y}_{\mathrm{i}}-\mathrm{q}\right) \text {. }
$$

$\rho_{\tau}$ is the well known quantile regression check function (see Koenker and Basset, 1978) and $\hat{\omega}_{j, i}$ are the individual weights which are calculated from the estimated propensity score of the treatment variable (see Firpo, forthcoming). Similar to the method of Hirano et al. (2003) for the case of mean effects, this procedure enables us to compute the quantiles of the latent variables $Y_{1}$ and $Y_{0}$ from observed variables.

The propensity score of receiving a high school degree is estimated using the series logit estimator (see Hirano et al., 2003), which is a series approximation of the log odds ratio. Firpo (forthcoming) shows consistency, asymptotic normality and semiparametric efficiency of the estimators for $\Delta^{\mathrm{OQTE}}$ and $\Delta^{\mathrm{QTET}}$ and proposes consistent variance estimators.

\section{Data and Determinants of Receiving a High School Degree}

The empirical part uses 21 samples from 1984 to 2004 drawn from the 21 waves of the West German Socio-Economic Panel (GSOEP), Haisken-DeNew and Frick (2005). Samples 4 and 7 of the GSOEP have been omitted. Sample 4 concentrates on immigrants to West Germany between 1984 and 1993. Sample 7, which is available only for 2002, 2003 and 2004, is an expansion of the GSOEP concentrated among high wage earners. Sample 4 is excluded, because there might be comparison 
problems between educational qualifications obtained abroad and in Germany. Several tests to check the sensitivity of the selected samples have been performed. Inclusion of sample 4 or 7 does not alter our basic findings.

The samples are restricted to male workers with a German citizenship aged 16 to 65 years (including dependent and self-employed workers). All observations with missing information on education, hourly wages and other variables needed were dropped (i.e., no imputations were used). The outcome variable is the real gross hourly wage which is obtained by the division of monthly salary by last month's hours of work for all workers including the self-employed. Individuals with vocational baccalaureate diplomas ("Fachabitur") are part of the control group. This degree allows for attending technical colleges but not universities. Wages are trimmed at the two percent highest and lowest observations on hourly wages in order to exclude somewhat extreme values from the estimation and to enhance comparability with other studies.

The treatment variable is the completion of high school, the highest German general educational qualification. The educational system in Germany is characterized by a beginning of school attendance at the age of six and of tracking at the age of ten. After four years of primary schooling, students basically have to choose between three types of secondary education: secondary schools ("Hauptschule" or "Realschule") or grammar school ("Gymnasium"), where graduates can obtain a high school degree. This degree is qualifying for attending technical colleges or universities. There are alternatives for receiving a high school degree, called second chance education. In our samples treatment is a binary variable and as such irrespective of how the degree has been acquired.

Table A2 of the appendix summarizes some descriptive findings from the samples of West German male workers aged 16 to 65, among those years of completed schooling. Note that years of education are not restricted to secondary education. It includes post secondary education at vocational schools or in the university system as well. The share of workers with a high school degree rose from 16 percent in 1984 to 25 percent in 2004. In the period of observation, the average number of years of education decreased for high school graduates from 17.2 to 16.7 years and increased from 11 to 11.5 years for controls. Thus, male workers with a high school degree invested on average 6.2 additional years of education in 1984 and 5.2 in 2004 which represents a drop of one year. The mean of real wages is increasing throughout the observation period, while hours worked are continuously declining in the control group. In 2004, workers belonging to the treatment group worked on average 1.2 hours longer per week (or 2.4 percent) and earned hourly $3.6 €$ (or 28 percent) more than members of the comparison group. 
For the present analysis the conditional independence assumption should hold. In Germany the choice of an education path leading to a high school degree depends on family background variables like parental education or job status of the parents (see for example Lauer and Steiner, 1999 and Dustmann, 2004). To explain the selection into grammar schools empirically and to thereby justify the identifying assumption, we use variables describing the family background. The GSOEP contains detailed information on the educational and vocational qualification of the parents, as well as their job position when the respective worker was fifteen years old. Even though the school choice takes place earlier for a majority of students (normally when they are ten to twelve years old), this variable is considered as a reasonable proxy of the social status of the parents. Information on the job position of the mother was not used due to some numerical problems. Furthermore, cohort effects turned out to be insignificant. The strong link between parental background and the educational choice of students in Germany lends some support for the conditional independence assumption.

Another factor influencing the choice of an education path might be individual ability at school entry. If ability influences both selection and outcome, omission of this variable will lead to biased results (see, for example, Griliches, 1977). The most popular way to solve this problem is by using an instrumental variables approach. But, for the question at hand and at least when using this dataset, no adequate instrumental variables are available. For this reason and especially for the prominent role parental background plays in the selection decision, we choose a conditional independence approach.

Table A3 in the appendix summarizes the means of the explaining variables for three exemplary cross-sections, 1984, 1994 and 2004. Parents of workers with a high school degree are better educated and fathers work in higher job positions. Not surprisingly, higher education of the parents and a higher job position of the father increases the probability of completing grammar school (Table A4). This probability is significantly negativly influenced if the father is a blue-collar worker, confirming the findings of the literature. Family background seems to be a strong influence for the decision to enter grammar school. Whether this is a consequence of economic wealth, preferences with respect to education or an interaction of these factors is a question for continuing research.

\section{Evolution of Quantile Treatment Effects}

This section discusses the econometric findings on the evolution of the distributional effects of a high school degree in Germany over the period from 1984 to 2004. In this period students participating from the educational expansion in the sixties reached the labour market. Furthermore the computer revolution changed the organisation of workplaces. Two different treatment effects have been estimated: the Overall Quantile Treatment Effect (OQTE) and the Quantile Treatment Effect on the 
Treated (QTET). The former is an estimate of the impact of the high school degree on the wage distribution of the whole population of West German male workers aged 16 to 65 , whereas the latter describes the impact on the subpopulation of high school graduates.

Figure 2 shows the evolution of the OQTE for nine percentiles $\left(10^{\text {th }}, 20^{\text {th }}\right.$ up to the $90^{\text {th }}$ quantile) together with 95 percent confidence intervals (based on the asymptotic results of Firpo, forthcoming). The point estimates of the OQTEs vary between 0.2 and 0.4. Even though they vary over quantiles as well as over time, the differences may in fact not be that large when taking into account the 95 percent confidence intervals. Therefore, at first glance the estimated OQTEs can be considered as rather stable. By and large, the empirical log differences are in the range of the 95 percent confidence intervals (Table A1 appendix). Thus, the (counterfactual) wage distributions of workers with and without a high school degree seem to have a similar shape. The positive effect, however, implies that the distribution of graduates is shifted to the right.

Furthermore, there is some indication of a diminishing effect of the high school degree. Figure 3 illustrates the OQTEs for all quantiles of the cross-sections 1984, 1994 and 2004. The comparison of the point estimates suggests a decline of the effect which is slightly higher for upper quantiles. Figure 4 compares the OQTE for all years and for the $10^{\text {th }}, 50^{\text {th }}$ and $90^{\text {th }}$ quantiles, which are often used in the literature on wage inequality. For a complete depiction, see Figure A1 in the appendix. However, since there is considerable variation in the point estimates, the evidence on a diminishing effect of the high school degree in Germany is not fully convincing.

Next, the results for the quantile treatment effect on the treated (QTET) are discussed (see Table A5 in the appendix). The point estimates of the QTET are lower than the OQTE and usually statistically insignificant. For comparison reasons, Table A5 contains the coefficients of a high school degree from ordinary quantile regressions with the QTET. With respect to the point estimates, estimates of ordinary quantile regressions are higher than the respective treatment effects. Since conventional quantile regressions do not take into account any self selection of schooling or optimization behaviour of the individuals in conjunction with heterogeneous treatment effects, the coefficient of a high school degree might overestimate the impact on the wage distribution, presumably as a result of the wellknown ability bias. 
Figure 2: The Evolution of the OQTE for nine quantiles, 1984-2004
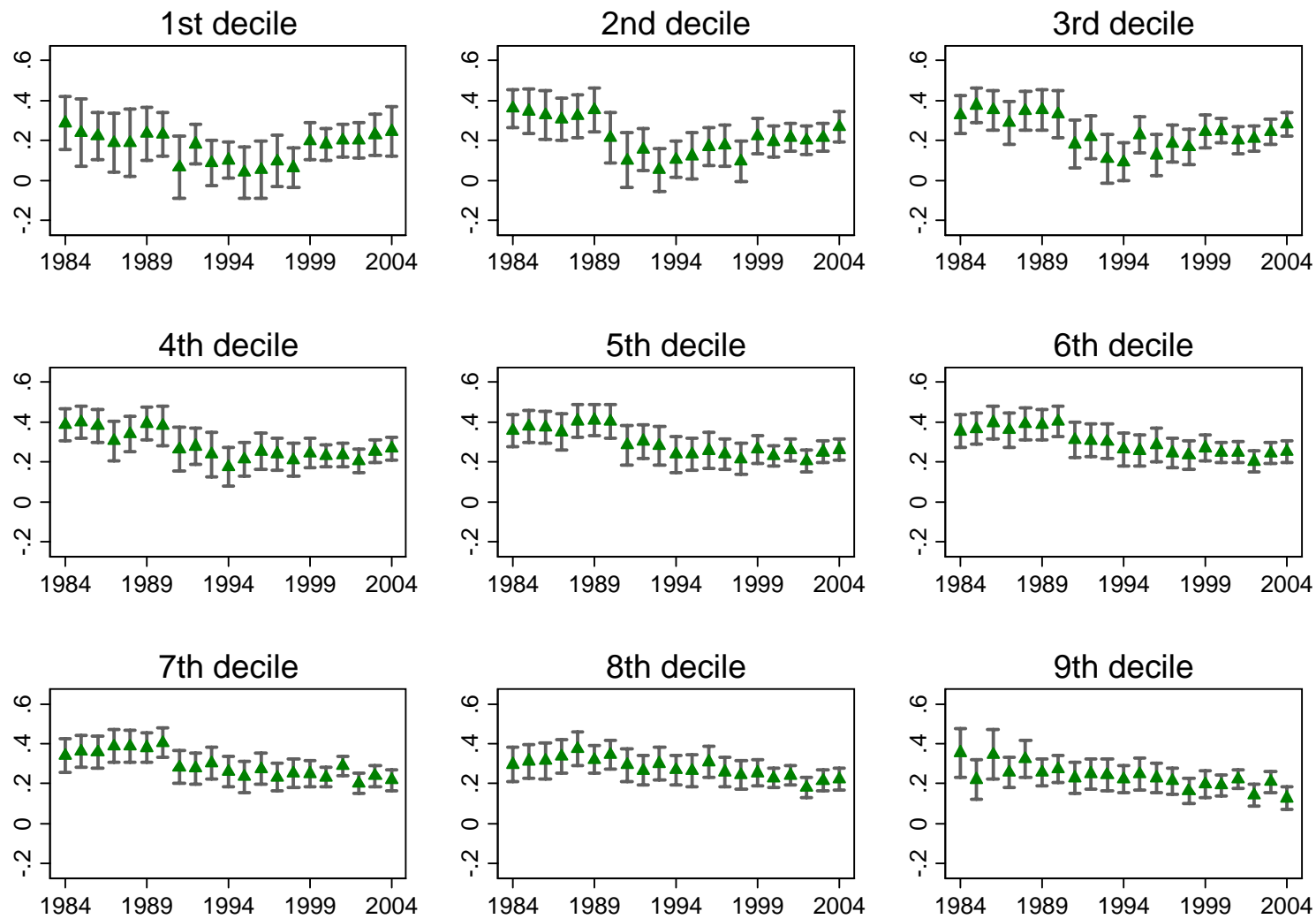

Source: GSOEP 1984-2004, sample of West German male workers aged 16 to 65; own calculations, see text.

When taking into account the endogeneity of a high school degree in the quantile treatment model, its impact on the wage distribution of high school graduates does not significantly differ from zero in most years and for most quantiles. This result seems to be in contrast to the positive overall quantile treatment effects. However, in our application, social status of the family is the driving force of grammar school attendance. This can be interpreted in the way that children of better educated parents are endowed with certain abilities and attitudes, opinions or behaviour that also drives selection into jobs.

The empirical results therefore shed some new light on the evolution of the impact of the high school degree in Germany over time, confirming its well known selectivity. Following this hypothesis, grammar school graduates do not profit from the degree as such, but mainly from their family background and inherited skills. If this interpretation is valid, our findings are in line with the literature on the selectivity effects of the German tracking system (Ammermüller and Pischke, 2006, Bildungsbericht, 2003, Dustmann, 2004, Lauer, 2005 and Schuetz et al., 2005, among others) and international evidence on the selectivity of schooling, Cunha and Heckman (2006). 
Figure 3: OQTE for West German Males over quantiles, 1984 (circles), 1994 (diamonds), 2004 (squares)

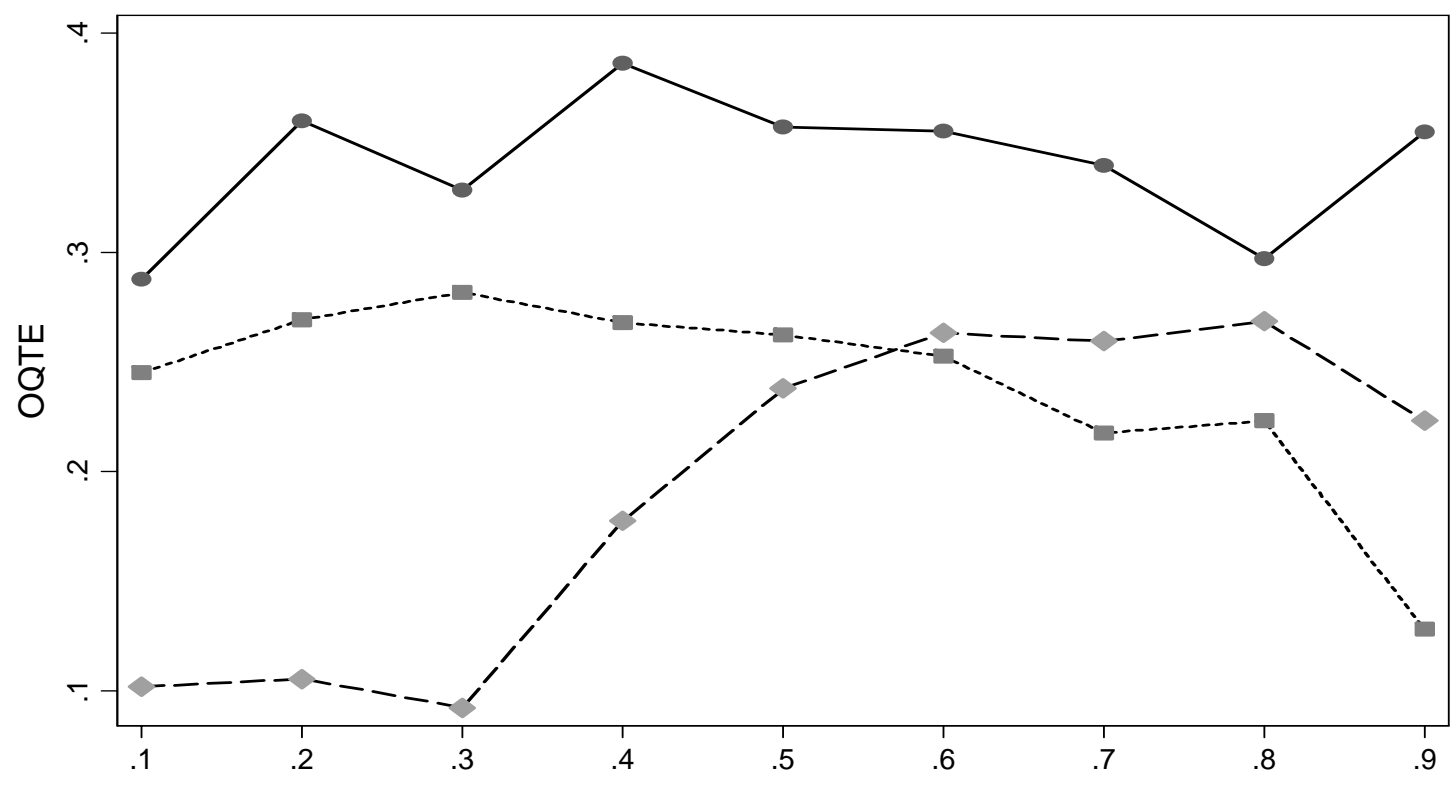

Source: GSOEP 1984-2004, sample of West German male workers aged 16 to 65; own calculations, see text.

Figure 4: The Evolution of OQTE from 1984 to $2004 ; 10^{\text {th }}$ (triangle), $50^{\text {th }}$ (diamonds), $90^{\text {th }}$ percentile (squares)

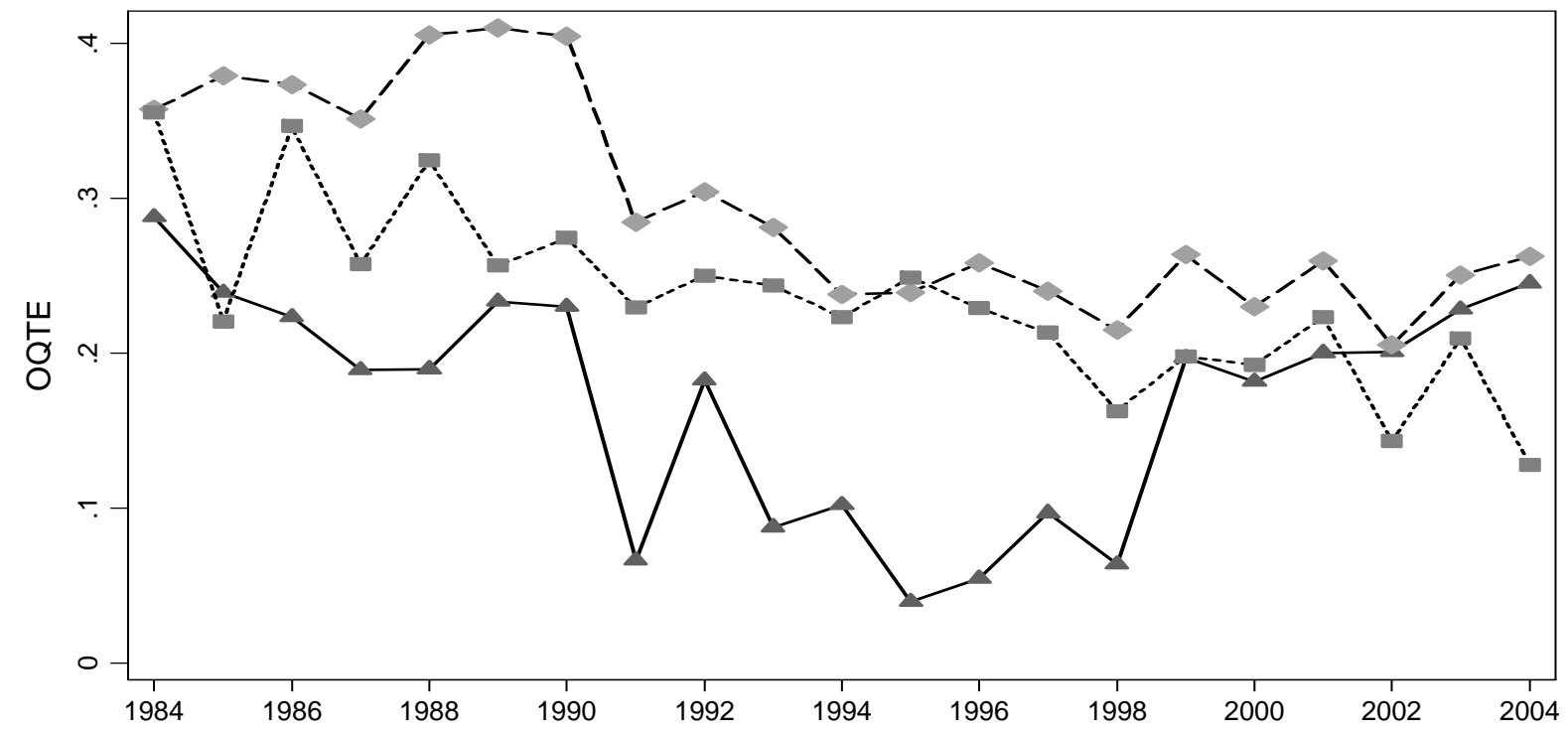

Source: GSOEP 1984-2004, sample of West German male workers aged 16 to 65; own calculations, see text. 


\section{Concluding Remarks}

The high school degree is the most important general educational qualification in Germany. Since 1960 the number of grammar schools which lead to this degree as well as the number and share of successful graduates in a cohort distinctly increased. Even though the influence of schooling on various labour market outcomes is a central topic of the economics of education, empirical knowledge on long run impacts of the rising share of workers with a high school degree in Germany is still rare. Given the debate on the possibly negative effect of the German educational system of early tracking on equality of educational opportunities, this is surprising. For educational policy reasons, empirical knowledge on long run impacts of the educational expansion on socio-economic outcomes such as employment or wages seems to be essential.

This paper is concerned with the impact of a high school degree on the wage distribution in the period from 1984 to 2004, which has not been investigated so far. In this period, the share of male workers with such a degree increased from 16 to 25 percent (in our GSOEP samples). Empirical knowledge of the impact of the high school degree on the whole wage distribution might be valuable for several reasons. General competencies learned at grammar school may yield higher returns in complex tasks and high wage jobs. In particular, grammar schools might be also helpful for individuals with low productivity. If labour market returns with a high school degree were higher for students with low productivity (and low wages), grammar schools could possibly provide a valuable tool for improving individual education and the productivity of the workforce.

The empirical findings result from comparisons of quantiles of the estimated wage distributions of individuals with and without a degree. Employing the estimator of Firpo (forthcoming), we distinguish the overall quantile treatment effects (OQTE) from the quantile treatment effects on the treated (QTET). The latter effect (QTET) assesses the impact of grammar school for those workers who studied there while the former (OQTE) assesses the impact for the whole population of workers in the samples. The samples consist of twenty-one cross-sections of German male workers from the GSOEP 1984 to 2004. Our findings suggest that the OQTEs are positive and significant, while the QTETs are statistically not different from zero. In addition, there seems to be some evidence that the impact of the high school degree on the upper part of the wage distribution has declined slightly.

In our application, social status of the family is the driving force of grammar school attendance, confirming earlier findings from the literature. Children of better educated parents seem to be endowed with attitudes and skills, which are also valuable in the labour market. Following this hypothesis, grammar school graduates did not profit from the degree as such, but instead from their family background and 
the skills acquired there. This furthermore suggests that the selection of students into grammer schools might have been too restrictive. For more workers higher education would have raised their productivity and wages.

The findings provide some new and further evidence on long run impacts of the educational expansion on the wage distribution. However, some caveats are necessary at this point. First of all, the estimates of the counterfactual wage distributions might be sensitive with respect to the share of workers with a high school degree. From a general equilibrium point of view, the results might differ in the case when the share of graduates continues to rise. It remains a task for future research to determine the relationship between the OQTE and the share of workers with a high school degree. Second, the empirical findings are based on representative data, in which the number of observations of workers with a high school degree is not that high. Some of the effects are therefore measured with a low degree of precision. Third, the mechanisms behind parental education, student effort and school choice as well as behind wages are a major topic of ongoing research. In fact, educational degrees of parents might only be a part of the factors which are relevant for the choice of schooling. Therefore, it remains a task for future research to investigate whether the results of this study remain stable with respect to different or additional influential factors and improved data. Future research to investigate skill formation in families seems to be fruitful for educational policy reason. 


\section{Appendix}

Table A1: Log Wage Differences: Treatment versus Control Group

\begin{tabular}{lccccc}
\hline Quantile & $\mathbf{1 9 8 4}$ & $\mathbf{1 9 8 9}$ & $\mathbf{1 9 9 4}$ & $\mathbf{1 9 9 9}$ & $\mathbf{2 0 0 4}$ \\
\hline $\mathbf{1 0}^{\text {th }}$ & 0.1806 & 0.2070 & 0.0903 & 0.1247 & 0.2232 \\
$\mathbf{2 0}^{\text {th }}$ & 0.2942 & 0.2956 & 0.0772 & 0.2012 & 0.2332 \\
$\mathbf{3 0}^{\text {th }}$ & 0.3102 & 0.3292 & 0.1100 & 0.2519 & 0.2475 \\
$\mathbf{4 0}^{\text {th }}$ & 0.3528 & 0.3408 & 0.1983 & 0.2543 & 0.2666 \\
$\mathbf{5 0}^{\text {th }}$ & 0.3607 & 0.3478 & 0.2561 & 0.2658 & 0.2427 \\
$\mathbf{6 0}^{\text {th }}$ & 0.3711 & 0.3603 & 0.2738 & 0.2694 & 0.2579 \\
$\mathbf{7 0}^{\text {th }}$ & 0.3506 & 0.3657 & 0.2719 & 0.2513 & 0.2231 \\
$\mathbf{8 0}^{\text {th }}$ & 0,3726 & 0.3567 & 0.2693 & 0.2813 & 0.2512 \\
90th $^{\text {average }}$ & 0.3772 & 0.2794 & 0.2210 & 0.2022 & 0.1529 \\
\hline Source: GSOEP & 0.3090 & 0.3008 & 0.1851 & 0.2202 & 0.2150 \\
\hline
\end{tabular}

Source: GSOEP 1984-2004, sample of West German male workers aged 16 to 65; see text; own calculations. 
Table A2: Means of Wages and Hours for the Treatment and Control Group

Treatment group (with Abitur)

Control group (without Abitur)

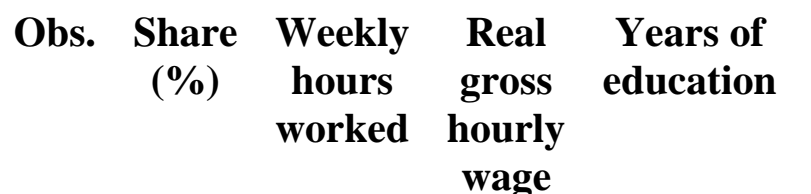

Obs. Share Weekly Real Years of

\begin{tabular}{|c|c|c|c|c|c|c|c|c|c|c|}
\hline & & $(\%)$ & $\begin{array}{c}\text { hours } \\
\text { worked }\end{array}$ & $\begin{array}{c}\text { gross } \\
\text { hourly } \\
\text { wage }\end{array}$ & education & & $(\%)$ & $\begin{array}{c}\text { hours } \\
\text { worked }\end{array}$ & $\begin{array}{c}\text { gross } \\
\text { hourly } \\
\text { wage }\end{array}$ & education \\
\hline 1984 & 172 & 15.85 & 44.59 & 15.42 & 17.24 & 913 & 84.15 & 44.90 & 11.15 & 11.00 \\
\hline 1985 & 199 & 17.74 & 45.02 & 15.37 & 17.24 & 923 & 82.26 & 44.61 & 11.67 & 11.06 \\
\hline 1986 & 205 & 17.73 & 46.20 & 16.16 & 17.18 & 951 & 82.27 & 44.80 & 11.59 & 11.07 \\
\hline 1987 & 198 & 16.94 & 44.84 & 15.57 & 17.05 & 971 & 83.06 & 44.13 & 11.58 & 11.02 \\
\hline 1988 & 196 & 17.33 & 45.26 & 17.20 & 17.14 & 935 & 82.67 & 43.82 & 12.28 & 11.03 \\
\hline 1989 & 185 & 16.23 & 45.97 & 16.22 & 17.10 & 955 & 83.77 & 44.03 & 11.93 & 11.03 \\
\hline 1990 & 194 & 17.51 & 44.76 & 16.69 & 16.99 & 914 & 82.49 & 43.32 & 12.31 & 11.00 \\
\hline 1991 & 178 & 16.05 & 43.98 & 16.56 & 16.78 & 931 & 83.95 & 43.26 & 13.12 & 10.98 \\
\hline 1992 & 187 & 16.83 & 43.11 & 17.27 & 16.78 & 924 & 83.17 & 43.10 & 13.36 & 10.97 \\
\hline 1993 & 204 & 18.33 & 43.63 & 17.09 & 16.75 & 909 & 81.67 & 43.03 & 13.63 & 11.05 \\
\hline 1994 & 225 & 19.82 & 44.31 & 16.54 & 16.65 & 910 & 80.18 & 43.02 & 13.55 & 11.09 \\
\hline 1995 & 249 & 21.65 & 44.40 & 17.18 & 16.78 & 901 & 78.35 & 43.47 & 13.81 & 11.16 \\
\hline 1996 & 246 & 21.96 & 45.08 & 17.11 & 16.66 & 874 & 78.04 & 43.22 & 14.06 & 11.16 \\
\hline 1997 & 248 & 22.02 & 45.40 & 16.67 & 16.73 & 878 & 77.98 & 43.57 & 13.67 & 11.18 \\
\hline 1998 & 290 & 23.62 & 44.73 & 16.88 & 16.66 & 938 & 76.38 & 43.71 & 13.91 & 11.22 \\
\hline 1999 & 300 & 23.36 & 44.23 & 17.68 & 16.73 & 984 & 76.64 & 43.42 & 14.15 & 11.23 \\
\hline 2000 & 526 & 23.96 & 45.37 & 18.15 & 16.76 & 1669 & 76.04 & 43.93 & 14.56 & 11.41 \\
\hline 2001 & 524 & 23.94 & 44.54 & 18.17 & 16.73 & 1665 & 76.06 & 43.90 & 14.30 & 11.44 \\
\hline 2002 & 519 & 25.58 & 44.94 & 18.24 & 16.69 & 1510 & 74.42 & 43.73 & 14.79 & 11.45 \\
\hline 2003 & 495 & 25.70 & 44.72 & 18.98 & 16.72 & 1431 & 74.30 & 43.42 & 15.15 & 11.45 \\
\hline 2004 & 482 & 25.40 & 44.44 & 18.70 & 16.68 & 1416 & 74.60 & 43.21 & 15.10 & 11.49 \\
\hline
\end{tabular}

Source: GSOEP 1984-2004, sample of West German male workers aged 16 to 65; see text; own calculations. 
Table A3: Summary of Statistics, West German Males

\begin{tabular}{|c|c|c|c|c|c|c|}
\hline & \multicolumn{3}{|c|}{$\begin{array}{c}\text { Treatment group } \\
\text { (with Abitur) }\end{array}$} & \multicolumn{3}{|c|}{$\begin{array}{l}\text { Control group } \\
\text { (without Abitur) }\end{array}$} \\
\hline & 1984 & 1994 & 2004 & 1984 & 1994 & 2004 \\
\hline \multicolumn{7}{|l|}{ Schooling of the father } \\
\hline "Hauptschule" & 0.52 & 0.51 & 0.44 & 0.86 & 0.84 & 0.81 \\
\hline "Realschule" & 0.17 & 0.20 & 0.23 & 0.10 & 0.11 & 0.13 \\
\hline "Abitur, Fachhochschulreife" & 0.31 & 0.30 & 0.33 & 0.05 & 0.06 & 0.06 \\
\hline \multicolumn{7}{|l|}{ Schooling of the mother } \\
\hline "Hauptschule" & 0.63 & 0.62 & 0.51 & 0.91 & 0.88 & 0.85 \\
\hline $\begin{array}{l}\text { "Realschule, Abitur, } \\
\text { Fachhochschulreife" }\end{array}$ & 0.37 & 0.38 & 0.49 & 0.09 & 0.12 & 0.15 \\
\hline \multicolumn{7}{|l|}{ Job position of the father } \\
\hline "Blue-collar worker" & 0.21 & 0.24 & 0.18 & 0.54 & 0.54 & 0.54 \\
\hline "Self employed" & 0.22 & 0.17 & 0.15 & 0.17 & 0.13 & 0.13 \\
\hline "White-collar worker" & 0.31 & 0.31 & 0.41 & 0.18 & 0.22 & 0.24 \\
\hline "Civil servant" & 0.27 & 0.28 & 0.26 & 0.11 & 0.11 & 0.09 \\
\hline \multicolumn{7}{|l|}{$\begin{array}{l}\text { Vocational training of the } \\
\text { father }\end{array}$} \\
\hline "Technical Training" & 0.73 & 0.73 & 0.70 & 0.96 & 0.95 & 0.94 \\
\hline "Theoretical Training" & 0.27 & 0.27 & 0.30 & 0.04 & 0.05 & 0.06 \\
\hline
\end{tabular}

Source: GSOEP 1984-2004, sample of West German male workers aged 16 to 65; see text; own calculations. 
Table A4: The Determinants of "Abitur": Logit estimation

\begin{tabular}{|c|c|c|c|}
\hline & 1984 & 1994 & 2004 \\
\hline Constant term & $-0,7150 * *$ & $-0,5098 * *$ & 0,0477 \\
\hline \multicolumn{4}{|l|}{ Schooling of the father } \\
\hline "Hauptschule" & $-0,4000$ & $-0,5395 * *$ & $-0,3985^{* *}$ \\
\hline "Realschule" (reference) & $\cdot$ & . & . \\
\hline "Abitur, Fachhochschulreife" & $0,6067 *$ & 0,4180 & 0,3147 \\
\hline \multicolumn{4}{|l|}{ Schooling of the mother } \\
\hline "Hauptschule" & $-0,7441 * *$ & $-0,7457 * *$ & $-0,9222 * *$ \\
\hline $\begin{array}{l}\text { "Realschule, Fachhochschulreife, } \\
\text { Abitur" (reference) }\end{array}$ & . & . & . \\
\hline \multicolumn{4}{|l|}{ Job position of the father } \\
\hline "Blue-collar worker” & $-0,8090 * *$ & $-0,5079 * *$ & $-1,1013^{* *}$ \\
\hline "White-collar worker" (reference) & . & . & . \\
\hline "Self employed" & $-0,0669$ & 0,1266 & $-0,1931$ \\
\hline "Civil servant" & 0,2954 & $0,5528 * *$ & $0,3581 * *$ \\
\hline \multicolumn{4}{|l|}{ Vocational training of the father } \\
\hline "Technical Training” & . & . & . \\
\hline "Theoretical Training" & $0,8230 * *$ & $0,5851 *$ & $0,53069 * *$ \\
\hline Observations & 1085 & 1135 & 1898 \\
\hline Pseudo R2 & 0,1544 & 0,1361 & 0,1788 \\
\hline $\begin{array}{l}\text { Joint Significance of the variables } \\
\text { (p-value) }\end{array}$ & 0,000 & 0,000 & 0,000 \\
\hline
\end{tabular}

Source: GSOEP 1984-2004, sample of West German male workers aged 16 to $65 ; *=$ significant at the $10 \%$ level, ${ }^{* *}=$ significant at the $5 \%$ level; see text; own calculations. 
Table A5: Quantile Treatment Effect

\begin{tabular}{|c|c|c|c|c|c|c|}
\hline \multirow[t]{2}{*}{ Quantile } & \multicolumn{3}{|c|}{$\begin{array}{l}\text { obtained from a simple quantile } \\
\text { regression }\end{array}$} & \multicolumn{3}{|c|}{$\begin{array}{l}\text { QTET obtained from the Firpo } \\
\text { estimation }\end{array}$} \\
\hline & 1984 & 1994 & 2004 & 1984 & 1994 & 2004 \\
\hline 10th & $0,3853 * *$ & $0,1399 * *$ & $0,2370 * *$ & 0,1959 & 0,0987 & 0,2513 \\
\hline 20th & $0,3542 * *$ & $0,1945^{* *}$ & $0,2938 * *$ & 0,2616 & 0,0896 & 0,2719 \\
\hline 30th & $0,3567 * *$ & $0,2184 * *$ & $0,3102 * *$ & 0,2693 & 0,1031 & 0,2404 \\
\hline 40th & $0,3273 * *$ & $0,1938 * *$ & $0,2918 * *$ & 0,2787 & 0,1893 & $0,2495^{* *}$ \\
\hline 50th & $0,3483 * *$ & $0,2266^{* *}$ & $0,2834^{* *}$ & 0,2664 & 0,2237 & $0,2384 * *$ \\
\hline 60th & $0,3628 * *$ & $0,2325^{* *}$ & $0,2708 * *$ & 0,2313 & 0,2474 & 0,2345 \\
\hline 70th & $0,3449 * *$ & $0,2560 * *$ & $0,2635^{* *}$ & 0,2037 & 0,2213 & 0,2005 \\
\hline 80th & $0,3595 * *$ & $0,2653 * *$ & $0,2729 * *$ & 0,2877 & 0,2121 & 0,2058 \\
\hline 90th & $0,3583 * *$ & $0,2650 * *$ & $0,2127 * *$ & 0,2733 & 0,1611 & 0,1031 \\
\hline
\end{tabular}

Source: GSOEP 1984-2004, sample of West German male workers aged 16 to $65 ; * *=$ significant at the $5 \%$ level; see text; own calculations. 
Figure A1: Evolution of OQTE of Abitur over Quantiles, 1984-2004
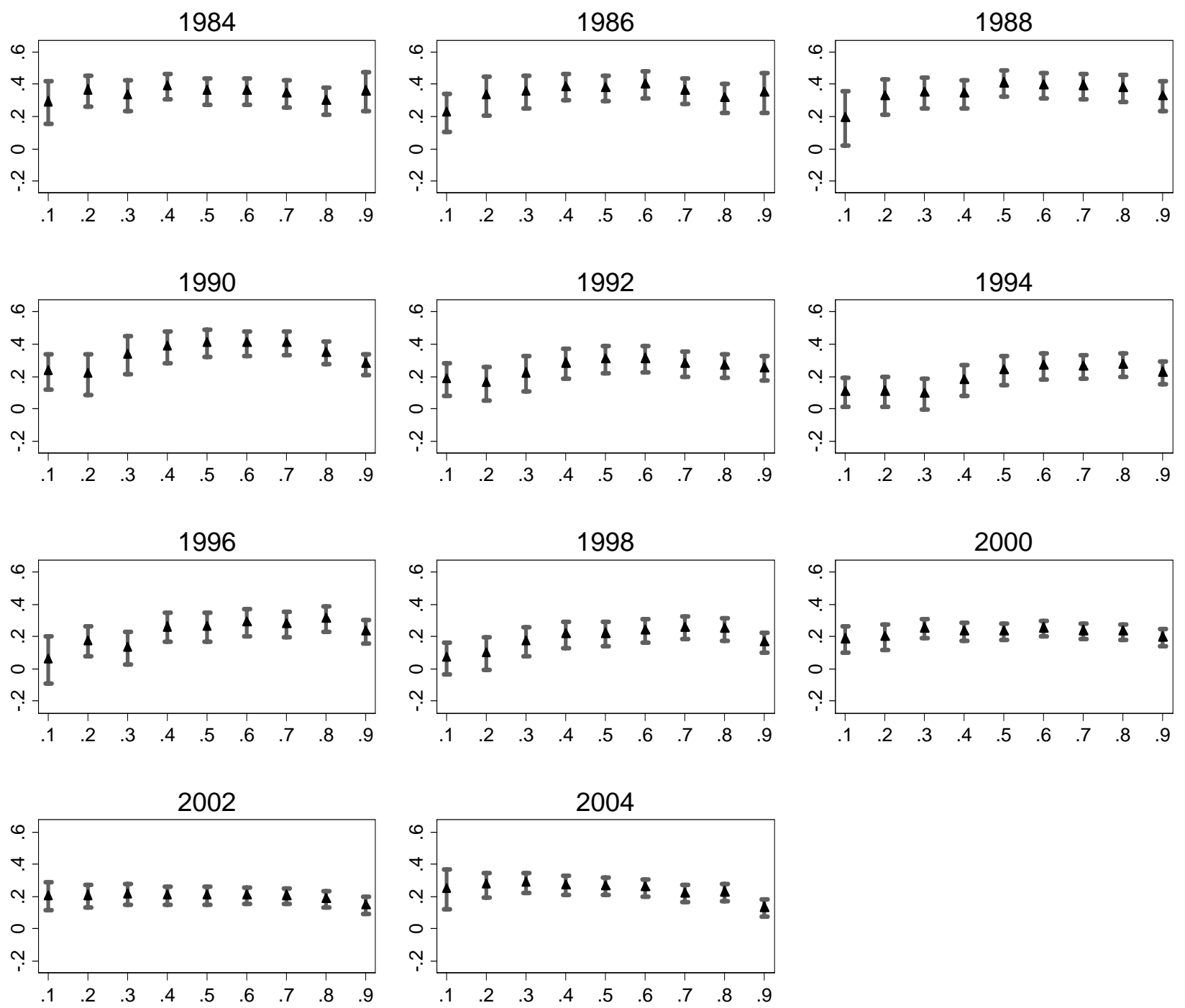

Source: GSOEP 1984-2004, sample of West German male workers aged 16 to 65; own calculations, see text. 


\section{References}

Ammermüller, A. and J.-S. Pischke (2006), Peer Effects in European Primary Schools: Evidence from PIRLS, ZEW Discussion Paper 06-27.

Angrist, J. (2004), Treatment Effect Heterogeneity in Theory and Practice, Economic Journal 114, C52-C83.

Autor, D., L. Katz and M. Kearney (2006), The Polarization of the U.S. Labor Market, The American Economic Review 96 (2), 189-194.

Bildungsbericht (2003), Bildungsbericht für Deutschland, Kultusminister Konferenz, Leske \& Budrich, Opladen.

Blundell, R., L. Dearden and B. Sianesi (2005), Evaluating the Effect of Education on Earnings: Models, Methods and Results from the National Child Development Survey, Journal of the Royal Statistical Society, Series A, 168, 473-512.

Card, D. (2001), Estimating the Returns to Schooling: Progress on Some Persistent Econometric Problems, Econometrica, 69 (5), 1127-1160.

Chernozhukov, V. and C. Hansen (2005), An IV Model of Quantile Treatment Effects, Econometrica, 73, 245-261.

Cunha, F. and J. Heckman (2006), A Framework for the Analysis of Inequality, Journal of Macroeconomics (in press).

Dustmann, C. (2004), Parental Background, Secondary School Track Choice, and Wages, Oxford Economic Papers 56, 209-230.

Firpo, S. (forthcoming), Efficient Semiparametric Estimation of Quantile Treatment Effects, Econometrica.

Flossmann, A. and W. Pohlmeier (2006), Causal Returns to Education: A Survey on Empirical Evidence for Germany, Jahrbücher für Nationalökonomie und Statistik 226, 6-23.

Gernandt, J. and F. Pfeiffer (2006), Rising Wage Inequality in Germany, ZEW Discussion Paper 06-19.

Griliches, Z. (1977), Estimating the Returns to Schooling: Some Econometric Problems, Econometrica 45, 1-22.

Haisken-DeNew, J. and J. R. Frick (2005), DTC Desktop Companion to the German Socio-Economic Panel (SOEP), DIW Berlin.

Heckman, J. J., L. J. Lochner and P. E. Todd (2006), Earnings Functions, Rates of Return and Treatment Effects: The Mincer Equation and Beyond, In: Hanushek, E. A. and F. Welch (Eds.), Handbook of The Economics of Education, Vol. 1, North Holland, Amsterdam, 307- 485. 
Hirano, K., G. Imbens and G. Ridder (2003), Efficient Estimation of Average Treatment Effects Using the Estimated Propensity Score, Econometrica 71, 1161-1189.

Imbens, G. (2004), Nonparametric Estimation of Average Treatment Effects under Exogeneity: A Review, Review of Economics and Statistics 86, 4-29.

Koenker, R. and G. Bassett (1978), Regression Quantiles, Econometrica 46, 33-50.

Kohn, K. (2006), Rising Wage Dispersion, After All! The German Wage Structure at the Turn of the Century, IZA Discussion Paper 2098.

Lauer, C. (2005), Education and Labour Market Outcomes, Physica, Heidelberg.

Ludwig, V. and F. Pfeiffer (2006), Abschreibungsraten allgemeiner und beruflicher Ausbildungsraten - empirische Evidenz auf Basis subjektiver Einschätzungen, Jahrbücher für Nationalökonomie und Statistik, 226 (3), 260-284.

Müller, W. (1998), Erwartete und unerwartete Folgen der Bildungsexpansion, Kölner Zeitschrift für Soziologie und Sozialpsychologie Sonderhefte 38, 80-113.

Oreopoulos, P. (2006), Estimating Average and Local Average Treatment Effects of Education when Compulsory Schooling Laws Really Matter, The American Economic Review 96 (1), 152-175.

Schuetz, G., H. W. Ursprung and L. Woessmann (2005), Education Policy and Equality of Opportunity, IZA Discussion Paper 1906.

Spitz-Oener, A. (2006), Technical Change, Job Tasks and Rising Educational Demands: Looking Outside the Wage Structure, Journal of Labor Economics 24(2), 235-270.

Statistisches Bundesamt (2005a), Bildung und Kultur - Studierende an Hochschulen - Fachserie 11 Reihe 7, Wiesbaden (Metzler und Poeschel).

Statistisches Bundesamt (2005b), Grund- und Strukturdaten 2005, Wiesbaden (Statistisches Bundesamt). 